\title{
Avoiding Above-the-Knee Amputation with a Free Tibiofibular-Talocalcaneal Fillet Flap and Free Latissimus Dorsi Flap
}

\author{
Elena Garcia-Vilariño ${ }^{1, \odot ~ A l b e r t o ~ P e r e z-G a r c i a ~}{ }^{1} \quad$ Enrique Salmeron-Gonzalez ${ }^{1} \quad$ Alberto Sanchez-Garcia ${ }^{1}$
}

Jose Luis Bas² Eduardo Simon-Sanz'

\author{
${ }^{1}$ Department of Plastic Surgery, Hospital Universitario y Politécnico \\ La Fe, Valencia, Spain \\ ${ }^{2}$ Department of Traumatology, Hospital Universitario y Politécnico \\ La Fe, Valencia, Spain

\begin{abstract}
Address for correspondence Alberto Perez-Garcia, MD, Department of Plastic Surgery, Hospital Universitario y Politécnico La Fe, Avda. Fernando Abril Martorell 106, 46026 Valencia, Spain (e-mail: albertoperezgarci@gmail.com).
\end{abstract}

\begin{abstract}
Keywords

- fillet flap

- spare parts surgery

- free osteocutaneous

fillet flap

- amputation

- bone defect

Despite the advances achieved in reconstructive surgery, amputation is still the only option after some severe traumas. Preservation of the knee joint is considered a significant functional advantage. We present the case of a 39-year-old man with a comminuted Gustilo type IIIC open tibia fracture with massive bone loss. To achieve a well-fashioned amputation stump and preserve the knee joint, a free osteocutaneous fillet flap was performed, including the distal tibia and fibula, talus, and calcaneus bones. As a result, a sensate and long amputation stump covered with thick skin from the sole of the foot provided a stable coverage with an excellent functional result and adjustment to prosthesis.
\end{abstract}

\section{Introduction}

Despite the advances achieved in reconstructive surgery, amputation may be the only option after some "severe" traumas with massive loss of bone and muscle. ${ }^{1}$ Preservation of the knee joint is considered a significant advantage in terms of physical function; providing a stump with sufficient length will demand less energy for limb movement and provide better support for a prosthesis. ${ }^{2}$ On the other hand, guaranteeing the right quality stump is necessary to minimize complications in the future.

To our knowledge, this is the first report of an innervated osteocutaneous free fillet flap, including distal tibia, fibula, talus, and calcaneus bones for stump lengthening.

\section{Case Report}

A 39-year-old man was referred to our department after suffering a comminuted Gustilo type IIIC open tibia fracture with loss of bone substance affecting the right lower limb (-Fig. 1). Bone stabilization with an external fixator and a superficial femoral to tibioperoneal trunk bypass had been performed at another center. A secondary bypass failure was treated with a Fogarty occlusion catheter, and a compartment syndrome was developed due to ischemia-reperfusion injury, which had led to extended tissue damage.

When admitted at our hospital, he presented with muscle necrosis affecting all fascial compartments of the leg, and massive skin loss. The foot was insensate. After debridement, there was $3.5 \mathrm{~cm}$ of proximal tibial left and a massive diaphisarial bone defect ( - Fig. 2 ).

Due to the poor condition of the limb, amputation was decided. To extend the amputation stump and preserve the knee joint, an osteocutaneous fillet flap was planned, leveraging the proper condition of the sole of the foot. The flap included distal tibia, fibula, talus, and calcaneus bones ( - Fig. 3). To avoid kinking due to blood vessel redundancy, a free fillet flap was performed. It was based on the posterior tibial artery anastomosed end to end to the origin of the previous bypass. The greater saphenous vein at knee level was not available after having been used for the original arterial bypass. Therefore, the greater saphenous vein of the foot was anastomosed end to end to the descending genicular vein with an interpositioned vein graft from the contralateral limb. The tibial nerve of the flap was coapted
DOI https://doi.org/

$10.1055 / \mathrm{s}-0040-1708226$

ISSN 0970-0358.
(C)2020 Association of Plastic Surgeons of India
License terms

()(1) $\Theta \circledast$ 


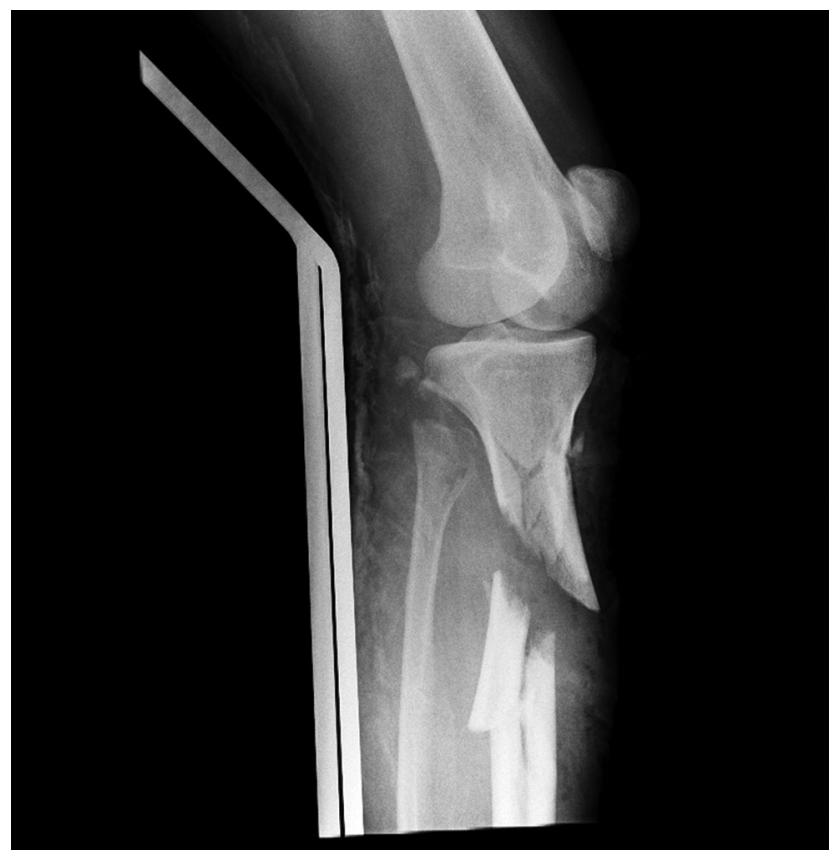

Fig. 1 Original lateral X-ray showing comminuted Gustilo-type IIIC open tibia fracture prior to debridement.

to the tibial division of the sciatic nerve in the fossa poplitea. A Hoffman-type external fixator was used to maintain proximal tibia in contact with distal tibia and fibula. A free latissimus dorsi flap was also performed for coverage, which was anastomosed end to side to the posterior tibial artery

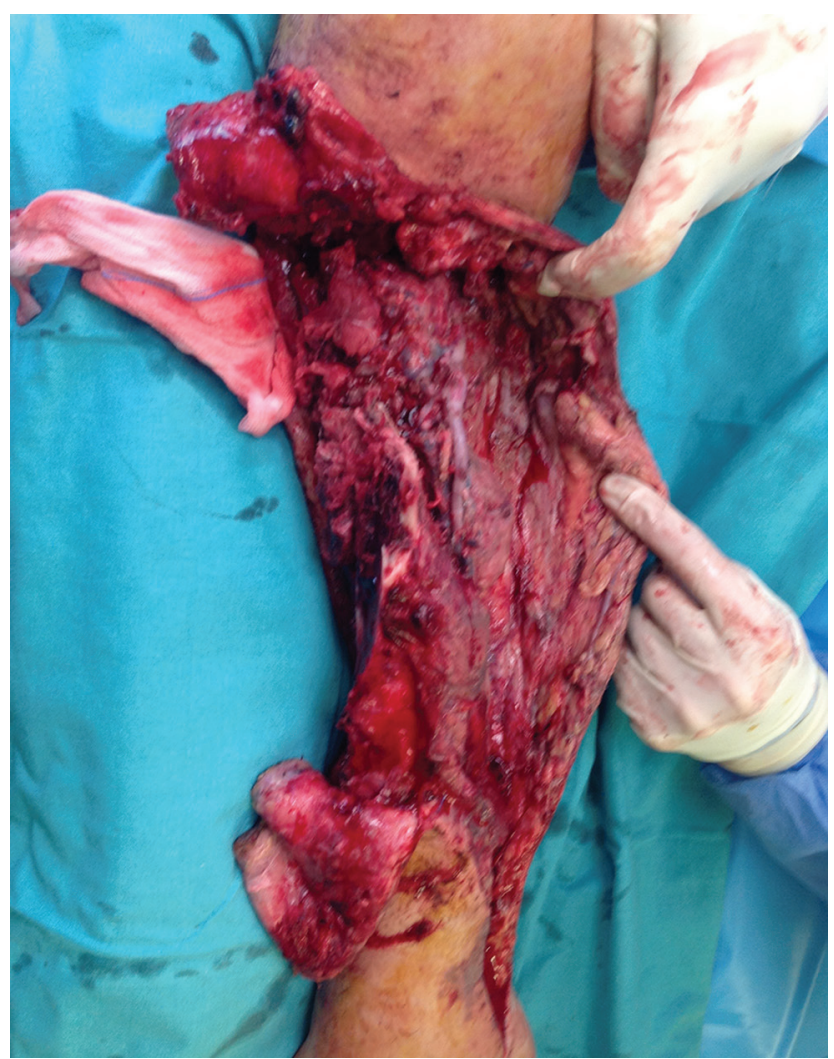

Fig. 2 Image showing massive necrosis and bone defect prior to debridement.

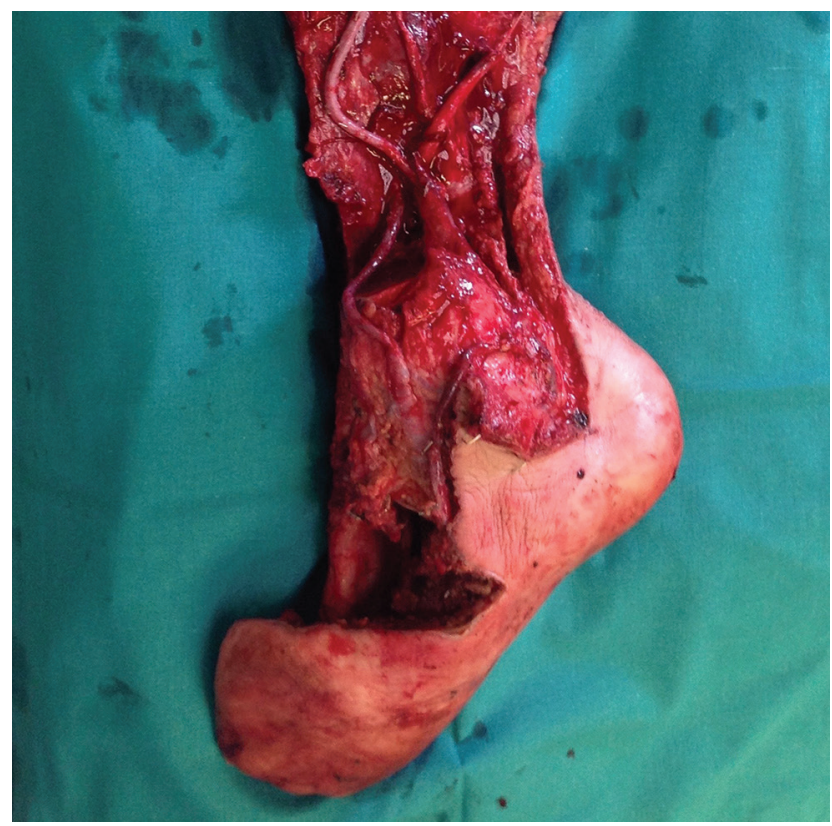

Fig. 3 Osteocutaneous flap showing left to right: greater saphenous vein of the foot, posterior tibial artery, and tibial nerve.

and lesser saphenous vein in the popliteal fossa ( - Fig. 4). Four weeks later, the external fixator was removed, and proximal tibia was fixated to distal tibia with cannulated screws.

No complications occurred during wound healing. Plantar sensitivity was recovered by the sixth month, with a two-point discrimination test result of $3 \mathrm{~cm}$. Knee range of motion was 0 to $90^{\circ}$ (-Fig. 5)

Subsequently, as instability of ankle joints caused him pain, tibiotalocalcaneal arthrodesis was performed with 3 canulated screws of $6.5 \mathrm{~mm}$, which were explanted after 18 months (-Fig. 6). Since the arthrodesis operation, the patient has been able to walk normally with proper adjustment to prosthesis, and pain issues have been solved ( - Fig. 7 ).

The utilization of an osteocutaneous fillet flap, in this case, allowed us to enlarge the tibial segment from $38 \mathrm{~mm}$ to the current $143 \mathrm{~mm}$ of amputation stump, with a thick and stable coverage.

\section{Discussion}

Primary amputation is recommended after significant distal trauma, extensive crush, severe nerve dysfunction, an ischemic limb with $<4 \mathrm{~h}$ warm ischemic time, segmental bone loss $>1 / 3$ length of the tibia, muscle loss in more than two compartments, and severe open foot injuries. ${ }^{3}$ When admitted to our center, the patient presented many of these conditions, and limb amputation was decided.

It is widely recognized that transtibial amputees perform better than either through-knee or transfemoral amputees, ${ }^{4}$ resulting in decreased rehabilitation time and better function. ${ }^{5}$ Below-the-knee amputations secondary to traumatic injuries do not always leave enough tissue to fashion a stump of sufficient length and durability to support a prosthesis. ${ }^{2}$ Although there are no categorical recommendations 


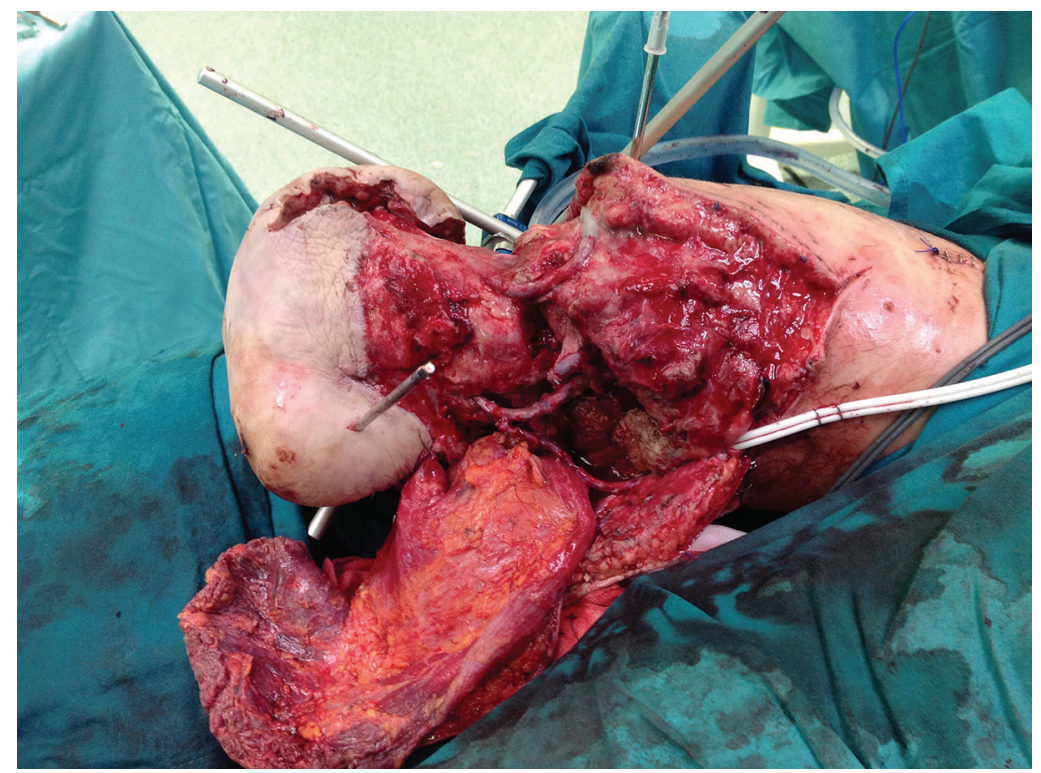

Fig. 4 Free latissimus dorsi flap and coverage defect before insetting.

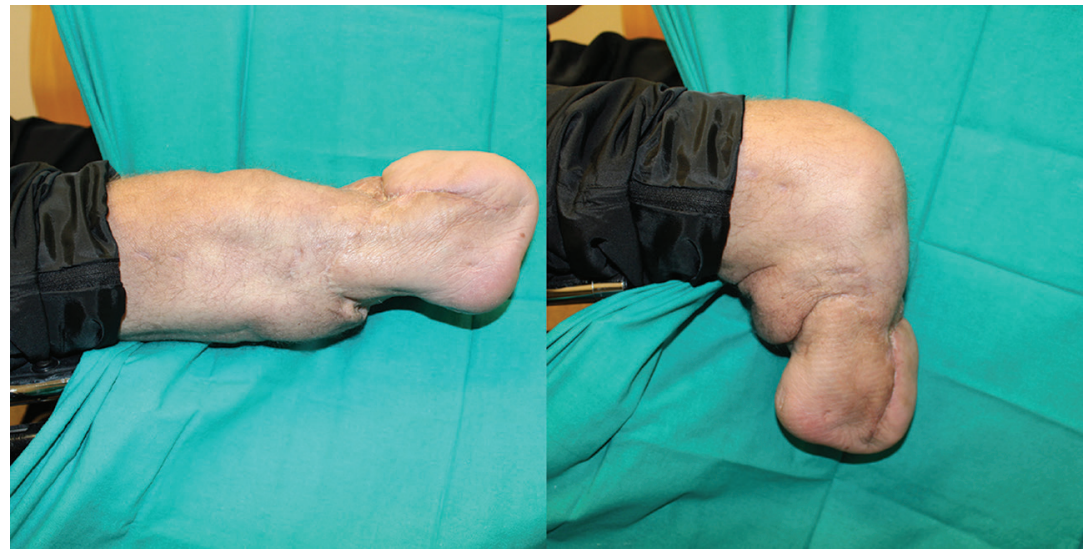

Fig. 5 Photograph of the final stump. Knee range of motion $0^{\circ}$ to $90^{\circ}$.

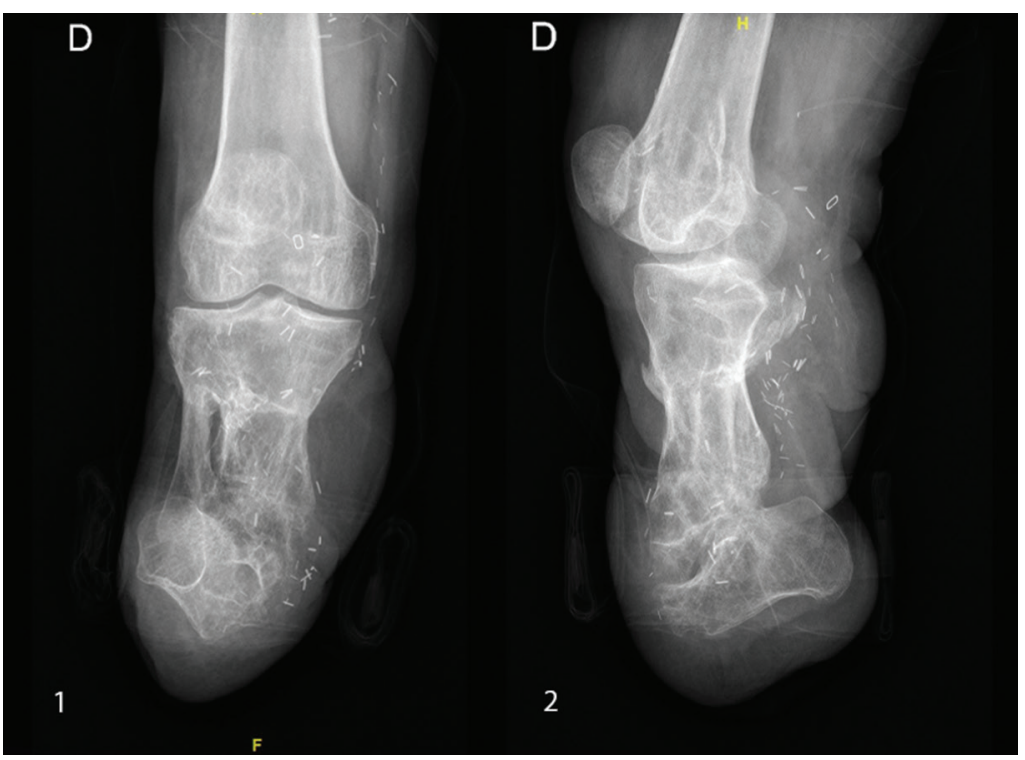

Fig. 6 Final radiography showing ankle arthrodesis. 


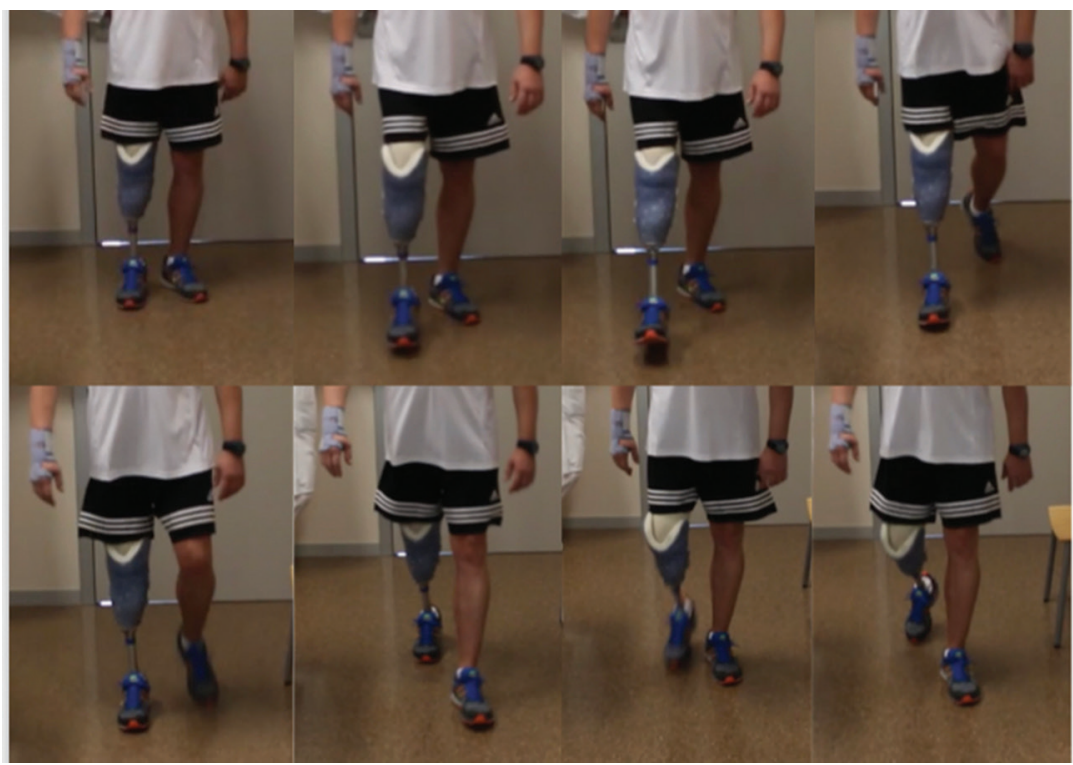

Fig. 7 Photographic sequence during gait with prosthesis.

regarding optimal length for a transtibial amputation stump, scientific literature generally recommends preserving at least $10 \mathrm{~cm}$ measured from the medial tibial plateau. ${ }^{6-8}$ To avoid a more proximal amputation, lengthening the stump by incorporating the concept of spare-part surgery may allow reconstruction, preventing the need for other donor sites. ${ }^{9}$

Composite flaps can be harvested from the amputated limb, allowing to transform an above-the-knee into a belowthe-knee amputation. Other osteocutaneous fillet flaps with calcaneus bone have been described in literature. We, however, have not found previous reports showing preservation of the 4 bones and a free innervated osteocutaneous flap that contributed to preserve as much limb length as possible and an optimal supporting area.

Moreover, leveraging preserved plantar foot sensation, and the well-padded and thick skin from the sole of the foot provided the best available coverage for an amputation stump. Although tibial nerve injury has classically been considered as an indication for amputation in open tibia fractures, if a high-quality nerve repair can be performed, with direct coaptation of the tibial nerve, foot sensation may be restored. ${ }^{10}$ By preserving the tibial nerve, we were able to provide sensation to the stump, as well as avoiding phantom limb pain and distal neuromas of the tibial nerve.

As for the limitations of this procedure, the process involved the performance of consecutive surgeries. Therefore, it should be performed in selected candidates at a young age and without relevant comorbidities. To avoid further surgical procedures, tibiotalocalcaneal arthrodesis can be performed in the first surgery. In addition, the patients may require the use of crutches in the future, and the absence of the latissimus dorsi muscle may complicate their adjustment. However, the primary muscles required for ambulation with crutches include not only latissimus dorsi but also the scapula stabilizers, shoulder depressors, shoulder extensors, elbow extensors, and finger flexors. ${ }^{11}$
Despite the high number of interventions and the subsequent costs, achieving an adequate-quality stump and optimal support for prosthesis adjustment lead to better functioning and early reincorporation to labor. ${ }^{1}$ Some of the interventions involves a high degree of complexity which requires an experienced microsurgery team.

\section{Conclusion}

Transtibial amputees have proved higher functional results and better adjustment to prosthesis than through-knee or transfemoral amputees. We report a new technique to extend the stump with a composite free fillet flap that preserves not only the sensitive skin coverage of the sole of the foot but also the distal tibia, fibula, talus, and calcaneus bone.

\section{Funding Information}

None received.

\section{Conflict of Interest}

The authors have no competing interests to declare.

\section{References}

1 Hansen ST Jr. The type-IIIC tibial fracture. Salvage or amputation. (editorial) J Bone Joint Surg Am 1987;69(6):799-800

2 Januszkiewicz JS, Mehrotra ON, Brown GE. Calcaneal fillet flap: a new osteocutaneous free tissue transfer for emergency salvage of traumatic below-knee amputation stumps. Plast Reconstr Surg 1996;98(3):538-541

3 Nanchahal J, Nayagam S, Khan U, et al. Standards for the management of open fractures of the lower limb (published on behalf of the British Association of Plastic, Reconstructive and Aesthetic Surgeons and British Orthopaedic Association). London, UK: RSM Press; 2009

4 MacKenzie EJ, Bosse MJ, Castillo RC, et al. Functional outcomes following trauma-related lower-extremity amputation. J Bone Joint Surg Am 2004;86(8):1636-1645 
5 Gonzalez EG, Corcoran PJ, Reyes RL. Energy expenditure in below-knee amputees: correlation with stump length. Arch Phys Med Rehabil 1974;55(3):111-119

6 Vitali M, Robinson KP, Andrews BG, et al. Amputations and prostheses, 2nd ed. London: Bailliere Tindall, 1986

7 Subbarao K, Bajoria S. The effect of stump length on the rehabilitation outcome in unilateral below-knee amputees for vascular disease. Clin Rehabil 1995;9(4):327-330

8 Khan MA, Javed AA, Rao DJ, Corner JA, Rosenfield P. Pediatric traumatic limb amputation: the principles of management and optimal residual limb lengths. World J Plast Surg 2016;5(1):7-14
9 Peng YP, Lahiri A. Spare-part surgery. Semin Plast Surg 2013;27(4):190-197

10 Pérez-García A, Salom M, Villaverde-Doménech ME, Baixauli F, Simón-Sanz E. Free microvascular rotationplasty with nerve repair for rhabdomyosarcoma in a 18-month-old patient. Microsurgery 2017;37(4):344-347

11 Segura A, Piazza SJ. Mechanics of ambulation with standard and spring-loaded crutches. Arch Phys Med Rehabil 2007;88(9):1159-1163 Mechanics of ambulation with standard and spring-loaded crutches 